\title{
Hypoglycaemic and anti-hyperglycaemic drugs for the control of diabetes
}

\author{
B Y C. J, B A I LEY \\ Department of Pharmaceutical Sciences, Aston University, Birmingham B4 7ET
}

The present review examines the mode of action of orally administered glucose-lowering agents used in the treatment of non-insulin-dependent diabetes mellitus (NIDDM). The review asks whether a distinction between 'hypoglycaemic' and 'anti-hyperglycaemic' agents is justified and desirable.

\section{THERAPEUTIC STRATEGY}

The control of hyperglycaemia is a key objective in the treatment of NIDDM, although many other clinical issues must be considered in the selection of an appropriate treatment regimen (Alberti \& Gries, 1988). Reducing blood glucose concentrations can delay and ameliorate those diabetic complications associated with chronic hyperglycaemia, particularly microvascular disease and neuropathy (Singh \& Nattrass, 1990). However, if such treatment is to be more than just palliative it should serve to correct, or at least partially obviate the underlying defects of glucose metabolism.

In NIDDM the principal defects are impaired glucose uptake and utilization by peripheral tissues such as muscle and excessive glucose production by the liver (DeFronzo, 1988). Insulin secretion in response to a glucose challenge is sluggish, but the overall magnitude of the response is not necessarily reduced, and may be substantially increased during early stages of the disease. Invariably there is tissue resistance to the action of insulin, reflecting one or more lesions in the cellular chain of events linking the insulin receptor with key enzymes and transport proteins.

\section{ORAL GLUCOSE-LOWERING DRUGS}

The main orally administered glucose-lowering agents used in the UK are the sulphonylureas and the biguanide metformin (Table 1 ). The various sulphonylureas differ in potency, pharmacokinetic properties and side effects (Ferner \& Chaplin, 1987; Lebovitz, 1990). So-called second-generation sulphonylureas, distinguished by more complex substitutions, show greater potency than first-generation compounds, and are, therefore, used at much smaller doses.

The glucose-lowering efficacy of sulphonylureas and metformin in NIDDM patients has been demonstrated in many studies reviewed elsewhere (Bailey \& Nattrass, 1988; Lebovitz, 1990). Comparisons between the two classes of drugs are complicated by differences in patient selection and the bias introduced by different assessment criteria. Metformin is mostly given to overweight patients and the dose is escalated slowly. Sulphonylureas are generally preferred for non-obese patients and tend to produce a greater glucose-lowering effect during the initial period of treatment. Comparisons have indicated that a similar degree of long-term glycaemic control is often achieved with either class of agent (Table 2), and there are similar primary and secondary failure rates. Thus, the choice of drug is ideally the best match between the clinical condition and 
Table 1. Oral glucose-lowering drugs

\begin{tabular}{|c|c|c|c|c|c|}
\hline Agent & Structure & & $\begin{array}{l}\text { Duration of glucose- } \\
\text { lowering effect* }\end{array}$ & Metabolites & Excretion route \\
\hline \multirow[t]{2}{*}{ Sulphonylureas } & $\mathrm{R}_{1} \in \mathrm{SO}_{2}$ - $\mathrm{NAr}-$ & $O S-R_{2}$ & & & \\
\hline & $R_{1}$ & $R_{2}$ & & & \\
\hline Acetohexamide $^{+}$ & $\mathrm{CH}_{3} \mathrm{CO}-$ & 0 & Intermediate & Active & Urine $(>60 \%)$ and bile \\
\hline Chlorpropamide $^{+}$ & ci- & $-\left(\mathrm{OH}_{2}\right)_{2} \mathrm{CH}_{3}$ & Long & Active & Urine (about $90 \%$ ) \\
\hline Glibenclamide ${ }^{\ddagger \S}$ & & 0 & Intermediate & Mostly inactive & Bile $(>50 \%)$ and urine \\
\hline Gliclazide & $\mathrm{CH}_{3}-$ & $-\widehat{x}$ & Intermediate & Mostly inactive & $\begin{array}{l}\text { Urine (about } 65 \% \text { ) } \\
\text { and bile }\end{array}$ \\
\hline Glipizide $^{\ddagger}$ & & 0 & Short-intermediate & Inactive & $\begin{array}{l}\text { Urine (about } 70 \% \text { ) } \\
\text { and bile }\end{array}$ \\
\hline Gliquidone & & 2 & Short-intermediate & Inactive & Bile (about $95 \%$ ) \\
\hline Tolazamide $^{\dagger}$ & $\mathrm{CH}_{3}-$ & & Short-intermediate & Weekly active & Urine (about $85 \%$ ) \\
\hline Tolbutamide & $c x_{3}$ & $-\left(\mathrm{CK}_{2}\right)_{3} \mathrm{CN}_{3}$ & Short & Inactive & Urine $(100 \%)$ \\
\hline $\begin{array}{l}\text { Biguanide } \\
\text { Metformin }\end{array}$ & $\alpha_{3}^{7-m}$ & & Short & Not metabolized & Urine (>95\%) \\
\hline
\end{tabular}

- Short. <12 h; intermediate, 12-24 h; long, >24 h.

‡ Second generation.

+ First generation.

$\$$ Glibenclamide is glyburide in the USA.

perceived needs of the patient compared with the activity profile, pharmacokinetic properties and side effects of the drug (Campbell, 1990).

\section{SULPHONYLUREAS AND INSULIN RELEASE}

In vitro studies have shown that sulphonylureas exert a direct and immediate stimulatory effect on insulin secretion by islet $\beta$ cells (Gorus et al. 1988; Panten et al. 1989). In the absence of glucose this is mainly transient (first-phase insulin secretion), followed by a smaller protracted effect (second-phase insulin secretion) which is more pronounced with second-generation sulphonylureas. When glucose is present the insulin-releasing effect is stronger, especially during the second phase, even at low glucose concentrations which are not sufficient to stimulate insulin secretion alone. Thus, sulphonylureas can increase the sensitivity of islet $\beta$ cells to the insulin-releasing effect of glucose. These effects are induced without entry of the drug into the $\beta$ cells, since the insulin-releasing potency is similar when the drug is covalently linked to dextran. In fact, sulphonylureas bind in a specific and saturable manner with a single type of binding site on the $\beta$ cell plasma membrane (Boyd, 1988; Panten et al. 1989). Photoaffinity labelling suggests that the binding site is a $140 \mathrm{~K}$ protein.

A good positive correlation exists between the membranc-binding affinities of sulphonylureas and their insulin-releasing potencies. These variables also correlate 


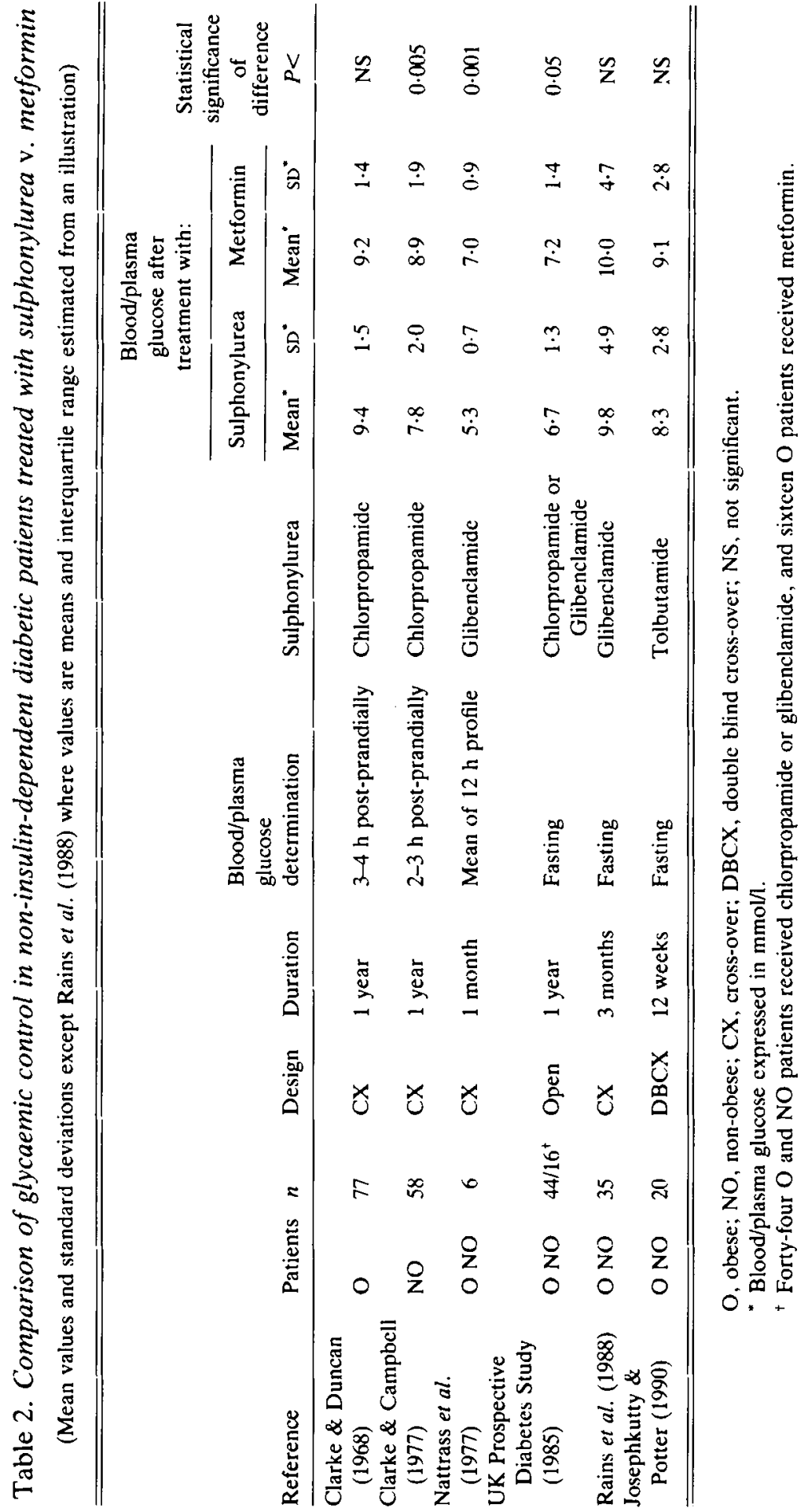


closely with the ability of sulphonylureas to reduce potassium ion efflux and increase the cytosolic calcium ion concentration of islet $\beta$ cells. Patch-clamp studies have demonstrated that sulphonylureas inhibit the activity of ATP-sensitive $\mathrm{K}^{\dagger}$ channels in the $\beta$ cell membrane, associated with depolarization of the $\beta$ cell membrane (Ashcroft \& Ashcroft, 1990). These observations have fostered the concept that sulphonylureas stimulate insulin release by binding to the $\beta$ cell membrane at sites associated with or closely allied to the ATP-sensitive $\mathrm{K}^{+}$channels. This results in closure of the channels which reduces $\mathrm{K}^{+}$efflux and causes membrane depolarization. $\mathrm{Ca}^{2+}$ influx is thereby triggered through voltage-dependent $\mathrm{Ca}^{2+}$ channels, and the increase in cytosolic $\mathrm{Ca}^{2+}$ elicits exocytosis of insulin granules (Malaisse \& Lebrun, 1990; Fig. 1).

The more complex substitutions of second-generation sulphonylureas may be responsible for improved anchorage at the binding site, thus conferring greater insulin-releasing potency. Indeed, compounds with a non-sulphonylurea moiety similar to secondgeneration sulphonylureas but lacking the sulphonylurea moiety can elicit insulin release by closure of ATP-sensitive $\mathrm{K}^{+}$channels, although their insulin-releasing potency is less than sulphonylureas (Henquin et al. 1987). Thus, the sulphonylurea group itself is not essential for the insulin-releasing effect. The possibility that certain sulphonylureas affect further sites at the $\beta$ cell cannot be discounted. Unlike other sulphonylureas, glibenclamide (glyburide in the USA) is highly lipophilic and substantial amounts enter the $\beta$ cell and become associated with the insulin secretory granules and mitochondria (Malaisse \& L.ebrun, 1990). Sulphonylureas potentiate the insulin-releasing effect of high glucose concentrations (e.g. $>10 \mathrm{mmol} / \mathrm{l}$ ) when the $\beta$ cells are already depolarized, and the ATP-sensitive $\mathrm{K}^{+}$channels are already almost completely closed (Ashcroft $e t$ al. 1988). A possible explanation is that not all $\beta$ cells in an islet are depolarized at the same time. Sulphonylureas inhibit $\beta$ cell phosphodiesterase (EC 3.1.4.1) activity and increase the generation of cyclic AMP which potentiates glucose-stimulated insulin release. Exposure to sulphonylyreas in vitro does not acutely stimulate $\beta$ cell glucose metabolism, although energy consumption is increased to service the increase in insulin release. Nevertheless, treatment with sulphonylureas in vivo increases the induction of glucokinase ( $E C$ 2.7.1.2), the enzyme which exerts rate-limiting control over $\beta$ cell glucose phosphorylation (Lenzen et al. 1986).

During the initial weeks and months of sulphonylurea treatment in NIDDM patients the insulin response to nutrient stimuli is typically enhanced, although basal insulin concentrations are not necessarily changed (Kolterman et al. 1984; O'Meara et al. 1990). The accompanying improvement in glycaemic control is not closely correlated with the increased insulin response, presumably due to variations of insulin resistance. However, improved glycaemic control does correlate with decreased hepatic glucose output (HGO) and increased peripheral glucose disposal.

During chronic administration of sulphonylureas the insulin-releasing effect is prone to diminish or become lost (Kolterman et al. 1984; Faber et al. 1990; Lebovitz, 1990), although some patients still secrete more insulin than before treatment, relative to their lower glucose concentrations during treatment (Judzewitsch et al. 1982). The insulinreleasing effect of second-generation sulphonylureas is claimed to persist longer than first-generation compounds, but the effect is generally lost within 1-2 years of treatment. Why the insulin-releasing effect should diminish during chronic treatment is unknown, but evidence that sulphonylureas decrease proinsulin biosynthesis and reduce total pancreatic insulin content may not be unrelated. 


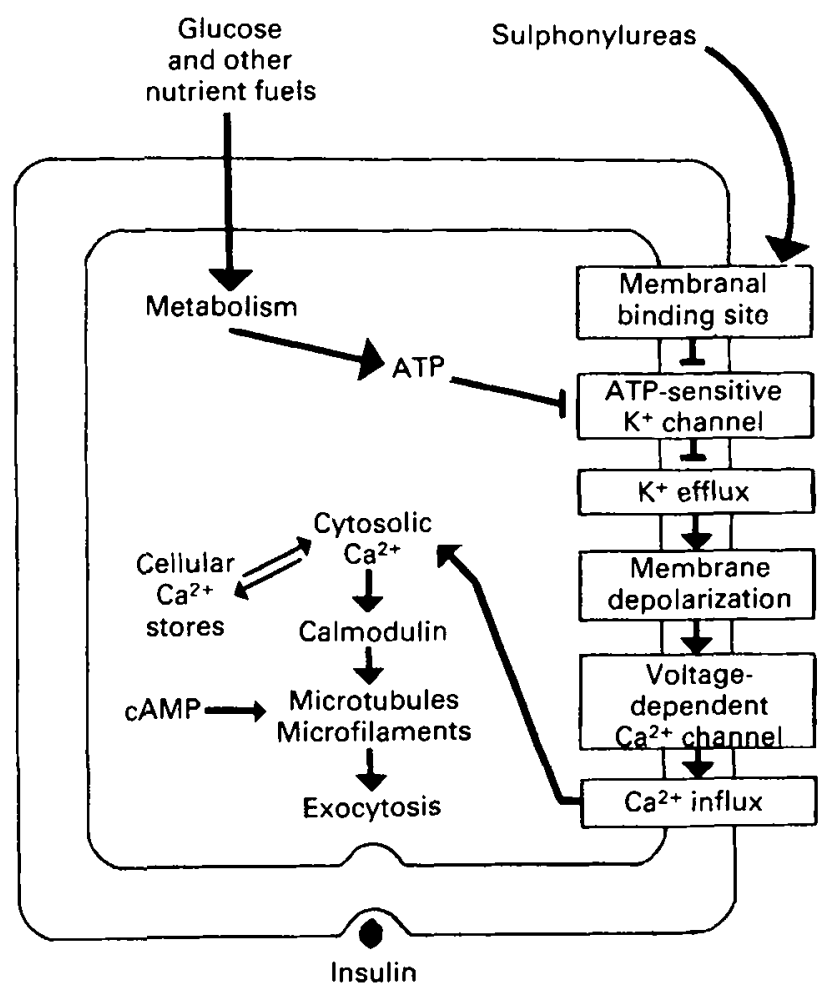

Fig. 1. Scheme to illustrate proposed mechanism through which sulphonylureas stimulate insulin release. $\rightarrow$, stimulatory effect:

Sulphonylureas have a transient stimulatory effect on glucagon release followed by a small protracted inhibitory effect (Sako et al. 1986), but clinical studies suggest that this is not sufficient to make a significant contribution to glycaemic control. Thus, factors other than those of islet origin must be important in the long-term glucose-lowering efficacy of sulphonylureas.

\section{EXTRAPANCREATIC EFFECTS OF SULPHONYLUREAS}

Extrapancreatic glucose-lowering effects of sulphonylureas are mainly directed towards the defects of glucose metabolism in liver, muscle and fat of NIDDM patients (Table 3). Some of these effects appear to involve the potentiation of insulin action, while others are not directly dependent on insulin. However, sulphonylureas alone are ineffective in the control of hyperglycaemia if insulin is absent, but they increase the hypoglycaemic effect of exogenous insulin.

Increased hepatic glucose output (HGO) in NIDDM is due mainly to increased gluconeogenesis, with a small contribution from increased glycogenolysis (Consoli et al. 1989). During the initial period of sulphonylurea treatment the additional release of insulin should more promptly suppress HGO and favour glycogenesis. Sulphonylureas 
Table 3. Extrapancreatic glucoregulatory effects of sulphonylureas

$\begin{aligned} & \uparrow \text { Insulin-mediated glucose uptake (muscle and fat) } \\ & \uparrow \text { Insulin-mediated glycogenesis (liver) } \\ & \uparrow \text { Insulin-mediated lipogenesis (liver and fat) } \\ & \uparrow \text { Glycolysis (liver) } \\ & \downarrow \text { Gluconeogenesis (liver) } \\ & \downarrow \text { Long-chain fatty acid oxidation (liver) } \\ & \downarrow \text { Lipolysis (fat) } \\ & \uparrow \text { Amino acid uptake (muscle and liver) }\end{aligned}$

$\uparrow$, Increase: $\downarrow$, decrease.

will also reduce the availability of gluconeogenic substrates such as alanine and lactate, consequent to the stimulation of muscle protein anabolism and potentiation of insulinstimulated glucose oxidation. However, sulphonylureas also act directly and rapidly on the liver to suppress gluconeogenesis. They increase the formation of fructose-2,6bisphosphate $\left(\mathrm{F} 2,6 \mathrm{P}_{2}\right)$ which results from inhibition of the enzyme A-kinase. Increased $\mathrm{F} 2,6 \mathrm{P}_{2}$ stimulates phosphofructokinase $(E C 2.7 .1 .11)$ and inhibits fructose 1,6 bisphosphatase (EC 3.1.3.46). This favours the conversion of fructose-6-phosphate to fructose1,6-bisphosphate, thereby increasing the glycolytic flux and suppressing gluconeogenesis (Okuno et al. 1988). It has been suggested that sulphonylureas may exert an uncoupling effect on oxidative phosphorylation in mitochondria. This would decrease the mitochondrial ATP:ADP ratio and reduce the activity of pyruvate carboxylase ( $E C$ 6.4.1.1). Such a mechanism could explain the ability of sulphonylureas to decrease the formation of phosphoenolpyruvate resulting in suppression of gluconeogenesis (White et al. 1988). Sulphonylureas inhibit long-chain fatty acid oxidation in the liver and decrease ketogenesis (Patel, 1986). This results from a direct inhibition of the enzyme carnitine palmitoyltransferase I ( $E C$ 2.3.1.21), possibly by competition with carnitine. Transfer of fatty acids into mitochondria is accordingly decreased, restricting energy supply and providing a further mechanism to suppress gluconeogenesis.

Sulphonylureas directly potentiate insulin-stimulated glycogenesis in the liver by enhancing the stimulatory effect of insulin on glycogen synthase (EC 2.4.1.2) and enhancing the inhibitory effect of insulin on phosphorylase $a(E C 2.4 .1 .1)$ (Caro, 1990; McGuinness, 1990). Treatment with sulphonylureas in vivo also increased the induction of hepatic glucokinase, probably due to raised insulin concentrations (Lenzen et al. 1986), facilitating the availability of phosphorylated glucose. The lipogenic effect of insulin is potentiated when hepatocytes are incubated with sulphonylureas for several hours (Salhanick et al. 1982), indicating the diversity of insulin effects that are enhanced by sulphonylureas in the liver.

Skeletal muscle is the major site of insulin-stimulated glucose uptake and metabolism, and impairment of this function in NIDDM leads to widespread disruption of nutrient homeostasis (DeFronzo, 1988). Sulphonylurea therapy enhances insulin-stimulated glucose disposal as testified by improved intravenous glucose tolerance and increased peripheral glucose disposal during glucose-clamp procedures (Kolterman et al. 1984; Beck-Nielsen et al. 1988). Although this is at least partly due to the improved glycaemic environment during sulphonylurea therapy (Firth et al. 1986), there is substantial evidence that sulphonylureas can also act directly on muscle to potentiate the gluco- 
regulatory effects of insulin. These actions of sulphonylureas on muscle are slowly generated, since administration of the drugs does not instantly affect glucose disposal by the forearm, and short-term incubation of isolated muscle with sulphonylureas does not affect glucose uptake. However, treatment with sulphonylureas in vivo for $>24 \mathrm{~h}$ measurably increases insulin-mediated glucose uptake by skeletal muscle (Lebovitz, 1990). Isolated skeletal muscle preparations are not suitable for long-term maintenance in vitro, but studies using the cultured rat L6 muscle cell line have confirmed that exposure to sulphonylureas directly potentiates insulin-mediated glucose uptake. The effect was maximal by $22 \mathrm{~h}$ and was not observed in the absence of insulin (Wang et al. 1987: Smith, 1990).

Sulphonylureas also directly potentiate insulin-mediated glucose uptake, glucose oxidation and lipogenesis in isolated adipocytes. Again, these effects require exposure to the drug for about $24 \mathrm{~h}$ to become maximal, and there is little or no effect in the absence of insulin (Maloff \& Lockwood, 1981; Jacobs \& Jung, 1985). Sulphonylureas suppress lipolysis by adipocytes and liver, possibly by increasing phosphodiesterase activity in these tissues (Osegawa et al. 1982).

The cellular mechanism through which sulphonylureas potentiate insulin action remains to be elucidated. Treatment with sulphonylureas in vivo has been reported to increase insulin-receptor binding in a range of tissues. However, this effect is not consistently observed, it does not correlate closely with the chronic glucose-lowering effect, and it is difficult to reproduce in vitro (Gavin, 1985). Sulphonylureas can enhance insulin action in some tissues without altering insulin-receptor binding, and studies in hepatocytes failed to show an effect on phosphorylation of the insulin receptor or on insulin-receptor kinase activity (Caro, 1990). This suggests a post-receptor site of action. In L6 cultured muscle cells sulphonylureas increased the number of glucose transporters, and in the presence of insulin enhanced transporter activity (Wang et al. 1989). In adipocytes sulphonylureas potentiated insulin-induced recruitment of glucose transporters into the plasma membrane and increased transporter activity, but the total number of transporters was not significantly altered (Martz et al. 1989).

As noted previously, some effects of sulphonylureas are apparently independent of insulin. In the $\mathrm{BC}_{3} \mathrm{H} 1$ myocyte cell line sulphonylureas stimulate glucose uptake in the absence of insulin, possibly by direct activation of protein kinase $C$ (EC 2.7.1.37) (Cooper et al. 1990). High-affinity binding sites for sulphonylureas have been identified in heart, brain and adipocytes, as well as islet $\beta$ cells, and a suppressive effect on ATP-sensitive $\mathrm{K}^{+}$channels has been reported in cardiac, skeletal and smooth muscle (Ashcroft \& Ashcroft, 1990).

\section{ACTIONS OF METFORMIN: COMPARISON WITH SULPHONYLUREAS}

The glucose-lowering effect of metformin may be contrasted with sulphonylureas in several important respects. Metformin does not act by stimulating insulin secretion or by affecting the release of other major glucoregulatory hormones. Therapeutic efficacy is due to extrapancreatic actions which are superficially similar to those of sulphonylureas, namely increased insulin-mediated glucose disposal and decreased HGO (Bailey \& Nattrass, 1988). However, the mechanisms involved may be somewhat different, and metformin additionally increases glucose utilization by the small intestine (Table 4). 
Table 4. Glucoregulatory effects of metformin

$\uparrow$ Insulin-mediated glucose uptake (muscle and fat)

$\uparrow$ Insulin-mediated glucose oxidation (muscle and fat)

$\uparrow$ Insulin-mediated glycogenesis (muscle)

$\uparrow$ Anaerobic glucose metabolism (intestine)

$\downarrow$ Gluconeogenesis (liver)

$\uparrow$, Increase; $\downarrow$, decrease.

Metformin enhances various effects of insulin in insulin-resistant and hyperglycaemic states, but it has little effect on glycaemia in non-diabetic individuals unless glucose concentrations are artificially raised. Some effects appear to be independent of insulin, but metformin is not effective in patients devoid of insulin. Insulin-mediated glucose uptake, glucose oxidation and glycogenesis by skeletal muscle are increased by metformin in non-insulin-dependent diabetic states (Bailey \& Puah, 1986). Increased insulin-mediated glucose uptake, glucose oxidation and lipogenesis have also been observed with adipose tissue, plus increased insulin-induced recruitment of glucose transporters into the plasma membrane. Like sulphonylureas, metformin can increase insulin-receptor binding, but this does not correlate with the metabolic effects. Indeed, most of the metabolic effects have been duplicated under conditions in which metformin does not measurably change insulin-receptor binding (Bailey, 1988). Increased phosphorylation and kinase activity of insulin receptors have been observed after metformin treatment in vivo (Rossetti et al. 1990). However, in vitro experiments have shown that insulin-mediated glucose uptake can be increased by metformin without alteration of these variables, indicating a post-receptor site of action (Jacobs et al. 1986).

Metformin enters cells, but unlike biguanides with a long hydrophobic side chain, metformin exhibits only modest binding with membranal elements. The view that the glucose-lowering effect of biguanides results from inhibition of oxidative phosphorylation is not substantiated by metformin. Therapeutically active concentrations do not significantly alter ATP concentrations or redox state in the liver, and glucose oxidation is enhanced in muscle and fat. However, it is possible that the accumulation of high concentrations of metformin in the wall of the intestine does increase glucose utilization mainly by increasing anaerobic glycolysis (Bailey et al. 1990). This occurs during feeding and fasting, indicating that the glucose can be derived from the circulation. Much of the lactate so produced is extracted from the hepatic portal circulation by the liver. However, during the absorption of a meal, when the liver is challenged with raised concentrations of both lactate and glucose, there is often a rise in lactate concentrations in the peripheral circulation. Metformin decreases the rate of intestinal glucose absorption independently of its effect on intestinal glucose utilization. Sulphonylureas do not share the intestinal effects of metformin.

Gluconeogenesis is suppressed by both classes of compounds. In vitro studies indicate that low concentrations of metformin act synergistically with insulin to reduce gluconeogenesis, although supra-therapeutic concentrations are effective in the absence of insulin. Nevertheless metformin has not been shown to induce the variety of cellular effects on hepatic metabolism which are claimed to contribute to the anti-gluconeogenic effect of sulphonylureas. An anti-gluconeogenic effect of metformin is not consistently 
observed in vivo, and a likely explanation is that extra lactate produced by the intestine provides an additional supply of substrate to sustain gluconeogenesis. In this way an excessive fall in blood glucose is avoided.

There is typically a small decrease in body-weight during metformin therapy, whereas sulphonylureas promote weight gain. The effect of metformin cannot be attributed to increased lipolysis, and might reflect the increased expenditure of energy through non-oxidative glucose metabolism by the intestine. Increased glucose recycling and increased thermogenesis have also been suggested (Penicaud et al. 1989).

\section{HYPOGLYCAEMIC $v$. ANTI-HYPERGLYCAEMIC DRUGS}

A striking feature of metformin is that it characteristically lowers glucose concentrations to euglycaemia, but not below. Metformin does not cause clinical hypoglycaemia (arterial glucose concentration below about $2.2 \mathrm{mmol} / 1$ which invokes symptoms of neuroglycopenia) even when consumed in large quantities with suicidal intent. In contrast, sulphonylureas are prone to cause excessive glucose lowering with a wellrecognized risk of neuroglycopenia (Bailey et al. 1989). The estimated incidence of sulphonylurea-induced hypoglycaemia is $0.19-0.24$ per 1000 patient years, and the mortality risk is $0.014-0.033$ per 1000 patient years (Campbell, 1990). Thus it is appropriate to categorize sulphonylureas as 'hypoglycaemic', whereas metformin is conveniently termed 'anti-hyperglycaemic'.

Distinction between hypoglycaemic and anti-hyperglycaemic drugs could be used to indicate whether, for practical purposes, there is a risk of excessive glucose lowering which could result in neuroglycopenia. Table 5 lists a selection of drugs with hypoglycaemic or anti-hyperglycaemic properties (Bailey et al. 1989; Bailey \& Flatt, 1990). Hypoglycaemic drugs are likely to act in one or more ways to prevent adequate HGO, in particular to inhibit hepatic gluconeogenesis. This could be caused by inappropriately raised insulin concentrations, for example an overdose of exogenous insulin or unrestrained insulin secretion, especially if insulin release is stimulated at low glucose concentrations. Drugs which strongly mimic or potentiate insulin action can cause hypoglycaemia if they are sufficiently potent to override the normal counter-regulatory mechanisms which are brought into operation by excessive glucose-lowering. These include glucagon, catecholamines, glucocorticoids, growth hormone and autonomic reflexes. An agent able to suppress this mechanism is potentially hypoglycaemic.

Anti-hyperglycaemic drugs are unable or extremely unlikely to cause neuroglycopenia. An excessive fall in blood glucose is prevented because either they do not inhibit $\mathrm{HGO}$, or any suppression of $\mathrm{HGO}$ is not sufficient to override the normal

Table 5. Drugs with hypoglycaemic or anti-hyperglycaemic properties

\begin{tabular}{ll}
\hline Hypoglycaemic & Anti-hyperglycaemic \\
\hline Insulin & Metformin \\
Sulphonylureas & Guar gum \\
Ethanol & Fenfluramine \\
Quinine & $\alpha$-Glucosidase $(E C 3.2 .1 .20)$ inhibitors \\
Salicylates & Acipimox \\
$\beta$-Adrenoceptor antagonists & Bezafibrate \\
\hline
\end{tabular}


counter-regulatory mechanisms. Some anti-hyperglycaemic agents have additional safeguards to sustain HGO during fasting. In the case of metformin this is achieved by the supply of additional gluconeogenic substrate in the form of lactate from the intestine. Anti-hyperglycaemic drugs include those which reduce the rate of glucose entry into the circulation from the intestine. Such drugs may potentiate or mimic insulin action but without sufficient potency to prevent adequate HGO during fasting, and they are not expected to be potent stimuli for insulin secretion.

\section{REFERENCES}

Alberti, K. G. M. M. \& Gries, F. A. (1988). Management of non-insulin-dependent diabetes mellitus in Europe: a consensus view. Diabetic Medicine 5, 275-281.

Ashcroft. F. M., Ashcroft. S. J. H. \& Harrison. D. E. (1988). Properties of single potassium channels modulated by glucose in rat pancreatic $\beta$ cells. Journal of Physiology 400, 501-527.

Ashcroft, S. J. H. \& Ashcroft, F. M. (1990). Properties and functions of ATP-sensitive K-channels. Cellular Signalling 2, 197-214.

Bailey, C. J. (1988). Metformin revisited: its actions and indications for use. Diabetic Medicine 5, 315-320.

Bailey. C. J. \& Flatt, P. R. (1990). New Antidiabetic Drugs. London: Smith-Gordon.

Bailey, C. J., Flatt, P. R. \& Marks, V. (1989). Drugs inducing hypoglycaemia. Pharmacology and Therapeutics 42, 361-384.

Bailey, C. J.. Flatt, P. R.. Wilcock, C. \& Day, C. (1990). Antihyperglycaemic mechanism of action of metformin. In Frontiers in Diabetes Research. Lessons from Animal Diabetes, vol. 3. pp. 277-282 [E. Shafrir, editor]. London: Smith-Gordon.

Bailey, C. J. \& Nattrass, M. (1988). Treatment -- metformin. Balliere's Clinical Endocrinology and Metabolism 2, 455-476.

Bailey, C. J. \& Puah, J. A. (1986). Effect of metformin on glucose metabolism in mouse soleus muscle. Diabète et Métabolisme 12, 212-218.

Beck-Nielsen, H., Hother-Nielsen, O. \& Pedersen, O. (1988). Mechanism of action of sulphonylureas with special reference to the extrapancreatic effect: an overview. Diahetic Medicine 5, 613-620.

Boyd, A. E. (1988). Sulfonylurea receptors, ion channcls, and fruit flies. Diabetes 37, 847-850.

Campbell, I. W. (1990). Sulphonylureas and Metformin: Efficacy and Inadequacy. In New Antidiabetic Drugs, pp. 33-51 [C. J. Bailey and P. R. Flatt, editors]. London: Smith-Gordon.

Caro, J. F. (1990). Effects of glyburide on carbohydrate metabolism and insulin action in the liver. American Journal of Medicine 89, Suppl. 2A, 175-25S.

Clarke. B. F. \& Campbell, I. W. (1977). Comparison of metformin and chlorpropamide in non-obese, maturity-onset diabetics uncontrolled by diet. British Medical Journal 2, 1576-1578.

Clarke. B. F. \& Duncan, L. J. P. (1968). Comparison of chlorpropamide and metformin treatment on weight and blood glucose of uncontrolled obese diabetics. Lancet i, 123-126.

Consoli, A., Nurjham, N., Capani, F. \& Gevich, J. E. (1989). Predominant role of gluconeogenesis in incrcased hepatic glucose production in NIDDM. Diabetes 38. 550-557.

Cooper, R., Vila. M. C., Watson, J. E., Nair. G., Pollet, R. J., Standaert, M. \& Farese. R. V. (1990). Sulfonylurea-stimulated glucose transport association with diacylglycerol-like activation of protein kinase $C$ in BC3HI myocytes. Diabeles 39, 1399-1407.

DeFronzo, R. A. (1988). The triumvirate: $\beta$-cell, muscle. liver. A collusion responsible for NIDDM. Diabetes $37,667-687$.

Faber, O. K., Beck-Nielsen. H., Binder, C., Butzer, P., Damsgaard, E. M.. Froland, F., Hjolland, E.. Lindskov, H. O., Melander, A., Pedersen, O., Petersen, P., Sorensen, N. S. \& Watilin-Boll. E. (1990). Acute actions of sulfonylurea drugs during long-term trcatment of NIDDM. Diabetes Care 13, Suppl. 3. $26-31$.

Ferner, R. E. \& Chaplin. S. (1987). The relationship between the pharmacokinetics and pharmacodynamic effects of oral hypoglycaemic drugs. Clinical Pharmacokinetics 12, 379-401.

Firth, R. G. Bell, P. M. \& Rizza, R. A. (1986). Effects of tolazamide and exogenous insulin on insulin action in patients with non-insulin-dependent diabetes mellitus. New England Journal of Medicine 314, 1280-1286.

Gavin, J. R. (1985). Dual actions of sulfonylureas and glyburide: receptor and post-receptor effects. American Journal of Medicine 79, Suppl. 3B, 34-42. 
Gorus, F. K., Schuit, F. C., Veld, P. A. I. Gepts, W. \& Pipcleers, D. G. (1988). Interaction of sulfonylureas with pancreatic $\beta$-cells: a study with glyburide. Diabetes 37, 1090-1095.

Henquin, J. C.. Garrino, M. G., Nenquin, M. (1987). Stimulation of insulin release by benzoic acid derivatives related to the non-sulphonylurea moiety of glibenclamide: structural requirements and cellular mechanisms. European Journal of Pharmacology 141, 243-251.

Jacobs, D. B., Hayes, G. R., Truglia, J. A. \& Lockwood, D. H. (1986). Effects of metformin on insulin receptor tyrosine kinasc activity in rat adipocytes. Diabetologia 29, 798-801.

Jacobs, D. B. \& Jung, C. Y. (1985). Sulfonylurea potentiates insulin-induced recruitment of glucose transport carrier in rat adipocytes. Journal of Biological Chemistry 260, 2593-2596.

Josephkutty, S. \& Potter, J. M. (1990). Comparison of tolbutamide and metformin in elderly diabetic patients. Diabetic Medicine 7, 510-514.

Judzewitsch, R. G., Pfeiffer, M. A., Best, J. D., Beard, J. C., Halter, J. B. \& Portc, D. (1982). Chronic chlorpropamide therapy of noninsulin-dependent diabetes augments basal and stimulated insulin secretion by increasing islet sensitivity to glucose. Journal of Clinical Endocrinology and Metabolism 55, 321-328.

Kolterman. O. G., Gray, R. S., Shapiro, G., Scarlett. J. A., Griffin, J. \& Olefsky, J. M. (1984). The acute and chronic effects of sulfonylurea therapy in type II diabetic subjects. Diabetes 33, 346-354.

Lebovitz, H. E. (1990). Oral hypoglycemic agents. In Diabetes Mellitus, Theory and Practice, 4th ed.. pp. 554-574 [H. Rifkin and D. Porte, editors]. New York: Elsevier.

Lenzen, S., Tiedge, M. \& Panten, U. (1986). Glibenclamide induces glucokinase in rat pancreatic islets and liver. Biochemical Pharmacology 35, 2841-2843.

McGuinness, O. P. (1990). Effect of glyburide on hepatic glucose metabolism. American Journal of Medicine 89. Suppl. 2A, 26S-37S.

Malaisse, W. J. \& Lebrun, P. (1990). Mechanisms of sulfonylurea-induced insulin release. Diabetes Care 13, Suppl. 3, 9-17.

Maloff. B. L. \& Lockwood, D. H. (1981). In vitro effects of a sulfonylurea on insulin action in adipocytes: potentiation of insulin-stimulated hexose transport. Journal of Clinical Investigation 68, 85-90.

Martz, A., Jo, I. \& Jung, C. Y. (1989). Sulfonylurea binding to adipocyte membranes and potentiation of insulin-stimulated hexose transport. Journal of Biological Chemistry 264, 13672-13678.

Nattrass, M., Todd, P. G.. Hinks. L., Lloyd, B. \& Alberti, K. G. M. M. (1977). Comparative effects of phenformin, metformin and glibenclamide on metabolic rhythms in maturity-onset diabetics. Diabetologia $13,145-152$.

Okuno, S., Inaba, M., Nishizawa, Y., Inoue, A. \& Moril, H. (1988). Effect of sulphonylureas tolbutamide and glyburide on cAMP-dependent protein kinase activity in rat liver cytosol. Diabetes 37, 857-861.

O'Meara, N. M., Shapiro, E. T., van Cauter, E. \& Polonsky, K. S. (1990). Effect of glyburide on beta cell responsiveness to glucose in non-insulin-dependent diabetes mellitus. American Journal of Medicine $\mathbf{8 9}$, Suppl. 2A, 11S-16S.

Osegawa, M., Makino, H., Kanatsuka, A. \& Kumagai, A. (1982). Effects of sulfonylureas on membranebound low Km cyclic AMP phosphodiesterase in rat fat cells. Biochemica et Biophysica Acta 721, 289-296.

Panten, U., Burgfeld, J., Goerke, F., Rennicke, M., Schwanstecher, M., Wallasch, A., Zunkler, B. J. \& Lenzen, S. (1989). Control of insulin secretion by sulfonylureas, meglitinide and diazoxide in relation to their binding to the sulfonylurea receptor in pancreatic islets. Biochemical Pharmacology 38, 1217-1229.

Patcl, T. B. (1986). Effect of sulfonylureas on hepatic fatty acid oxidation. American Journal of Physiology 251, E241-E246.

Penicaud, L., Hitier. Y., Ferrc, P. \& Girard, J. (1989). Hypoglycaemic effect of metformin in genetically obese (fafa) rats results from an increased utilization of blood glucose by intestinc. Biochemical Journal 262, 881-885.

Rains, S. G. H., Wilson, G. A., Richmond, W. \& Elkeles, R. S. (1988). The effect of glibenclamide and metformin on serum lipoproteins in type 2 diabetes. Diabetic Medicine 5, 653-658.

Rossetti, L.. DeFronzo, R. A., Gherzi, R., Stein, P., Andraghetti, G., Falzetti, G., Shulman. G. I., Klein-Robbenhaar, E. \& Cordera, R. (1990). Effect of metformin treatment on insulin action in diabetic rats: in vivo and in vitro correlations. Metabolism 39, 425-435.

Sako, Y., Wasada, T., Umeda, F. \& Ibayashi. H. (1986). Effece of glibenclamide on pancreatic hormone release from isolated perfused islets of normal and cysteamine-treated rats. Metabolism 35, 944-949.

Salhanick, A. I., Konowitz, P. \& Amatruda, J. M. (1982). Potentiation of insulin action by a sulfonylurea in primary cultures of hepatocytes from normal and diabetic rats. Diabetes 32, 206-212.

Singh, B. M. \& Nattrass, M. (1990). Diabetes mellitus and the control of hyperglycaemia. In New Antidiabetic Drugs, pp. 1-18 [C. J. Bailey and P. R. Flatt, cditors]. London: Smith-Gordon. 
Smith, R. J. (1990). Effects of sulfonylureas on muscle glucose homeostasis. American Journal of Medicine 89 , Suppl. 2A, 38S-43S.

UK Prospective Diabetes Study (1985). UK prospective diabetes study. II. Reduction in HbAlc with basal insulin supplement, sulfonylurea, or biguanide therapy in maturity-onset diabetes. Diabetes 34, 793-798.

Wang, P. H., Beguinot, F. \& Smith, R. J. (1987). Augmentation of the effects of insulin and insulin-like growth factors I and II on glucose uptake in cultured rat skeletal muscle cells by sulfonylureas. Diabetologia 30, 797-803.

Wang, P. H., Moller, D., Flier, J. S., Nayak, R. C. \& Smith, R. J. (1989). Coordinate regulation of glucose transporter function, number and gene expression by insulin and sulfonylureas in L6 rat skeletal muscle cells. Journal of Clinical Investigation 84, 62-67.

White, C., Rashed, H. \& Patel, T. (1988). Sulfonylureas inhibit metabolic flux through rat liver pyruvate carboxylase reaction. Journal of Pharmacology and Experimental Therapeutics 246, 971-974. 